Webology, Volume 17, Number 1, June, 2020

\title{
\begin{tabular}{|l|l|l|l|}
\hline Home & Table of Contents & Titles \& Subject Index & Authors Index \\
\hline
\end{tabular}
}

\section{Digital Era in the Kingdom of Saudi Arabia: Novel Strategies of the Telecom Service Providers Companies}

\section{Arun Kumar Singh}

Assistant Professor, College of Computing and Informatics, Saudi Electronic University, Kingdom of Saudi Arabia-KSA. ORCID: 0000-0002-9974-4696. E-mail: a.singh@seu.edu.sa, arunsinghiiita@gmail.com

\section{Samidha Dwivedi Sharma}

Assistant Professor, College of Computing and Informatics, Saudi Electronic University, Kingdom of Saudi Arabia-KSA. ORCID: 0000-0001-5326-709X. E-mail: ssharma@seu.edu.sa, samidhad2000@gmail.com

Received December 20, 2019; Accepted June 20, 2020

\section{Abstract}

A revolution in wireless communication began in the first decade of the 20th century with the pioneering developments in radio communications by Guglielmo Marconi, who won the Nobel Prize in Physics in 1909. Other highly notable pioneering inventors and developers in the field of electrical and electronic telecommunications include Charles Wheatstone and Samuel Morse (telegraph), Alexander Graham Bell (telephone), Edwin Armstrong, and Lee de Forest(radio), as well as Vladimir K. Zworykin, John Logie Baird and Philo Farnsworth (television). In this paper we have discuss about the services and the quality with basic comparison between the different telecom companies. Numbers of telecom companies providing telecom services in Saudi Arabia which includes fixed and cellular phones as well as internet and issues relating to the provision of other services. Main telecom companies in Saudi Arabia are: STC, Mobily, Zain, ITC, GO Telecom (Etihad Atheeb Telecom), Bayanat and Arab Satellite Communications Organization. Saudi Telecom Company (STC) is the first company in Saudi Arabia, and then allowed Communications Commission to compete with other companies in Saudi Arabia and then it becomes a number one of telecom companies. In Saudi Arabia five companies are in competition: STC Mobile: STC includes landlines, mobile, mobile (phone) and Sawa; ITC (Integrated Telecom Company): second operator after STC and offers internet, broadband, connectivity and satellite services for businesses, consumers and wholesale; Mobily: It provide mobile and internet Fabraupetk (Fiber Optic) 
New Ground; Zain: its provide only mobile services; GO ATHEEB: A Saudi modern, with an Internet connection line is similar to Ground.

\section{Keywords}

Telecom Services; Fixed and Cellular Network; Internet; STC (Saudi Telecom Company); ZAIN (Telecom Company); Mobily (Telecom Company)

\section{Introduction}

This paper is about telecom service providers in Saudi Arabia which includes fixed and cellular phones as well as internet and issues relating to the provision of these services. Saudi Telecom Company (STC) is the first company in Saudi Arabia, and then allowed Communications Commission to compete with other companies in Saudi Arabia and then it becomes a number one of telecom companies in Saudi Arabia out of four companies (Communication and Information Technology Commission, Saudi Arabia, Annual Report, 2005):

1. STC Mobile: STC includes landlines, mobile services and mobile (phone).

2. Integrated Telecom Company (ITC) second operator after STC, established in 2005 and offers internet, broadband, connectivity and satellite services for businesses, consumers and wholesale.

3. Mobily: The UAE's telecommunications company, which is the mobile, internet and Fiber Optic New Ground.

4. ZIN Zain: A Kuwaiti company, which is providing the only mobile services.

5. GO ATHEEB: A Saudi modern, with an Internet connection line is similar to Ground.

Telecommunication is - according to Article 1.3 of the International Telecommunication Union's (ITU) Radio Regulations (RR) - defined as "Any transmission, emission or reception of signs, signals, writings, images and sounds or intelligence of any nature by wire, radio, optical or other electromagnetic systems." This definition is also identical to those contained in the Annex to the Constitution and Convention of the International Telecommunication Union (Geneva, 1992).

The word is often used in its plural form, telecommunications, because it involves many different technologies. Early means of communicating over a distance included visual signals, such as beacons, smoke signals, semaphore telegraphs, signal flags, and optical heliographs (Definition of Telecommunication, 2013; Collins English Dictionary, 2013; Vocabulary.com, 2013; Merriam-Webster Dictionary, 2013; Oxford Dictionaries, 2013). Other examples of pre-modern long-distance communication included audio messages such as coded drumbeats, lung-blown horns, and loud whistles. Modern technologies for longdistance communication usually involve electrical and electromagnetic technologies, such as telegraph, telephone, and teleprinter, networks, radio, microwave transmission, fiber optics, and communications satellites. 


\section{Key Concept Of Telecom}

\section{Telecommunications}

This is primarily divided up between wired and wireless subtypes. Overall though, a basic telecommunication system (Telecommunication, Dictionary.com, 2013) consists of three main parts that are always present in some form or another:

- A transmitter that takes information and converts it to a signal.

- A transmission medium, also called the "physical channel" that carries the signal. An example of this is the "free space channel".

- A receiver that takes the signal from the channel and converts it back into usable information for the recipient.

For example, in a radio broadcasting station the station's large power amplifier is the transmitter; and the broadcasting antenna is the interface between the power amplifier and the "free space channel". The free space channel is the transmission medium; and the receiver's antenna is the interface between the free space channel and the receiver. Next, the radio receiver is the destination of the radio signal, and this is where it is converted from electricity to sound for people to listen to.

Sometimes, telecommunication systems are "duplex" (two-way systems) with a single box of electronics working as both the transmitter and a receiver, or a transceiver. For example, a cellular telephone is a transceiver. The transmission electronics and the receiver electronics within a transceiver are actually quite independent of each other. This can be readily explained by the fact that radio transmitters contain power amplifiers that operate with electrical powers measured in watts or kilowatts, but radio receivers deal with radio powers that are measured in the microwatts or nanowatts. Hence, transceivers have to be carefully designed and built to isolate their high-power circuitry and their low-power circuitry from each other, as to not cause interference (Goggin Gerard, 2011).

Telecommunication over fixed lines is called point-to-point communication because it is between one transmitter and one receiver. Telecommunication through radio broadcasts is called broadcast communication because it is between one powerful transmitter and numerous low-power but sensitive radio receivers.

\section{Telecommunication Network}

A communications network is a collection of transmitters, receivers, and communications channels that send messages to one another. Some digital communications networks contain one or more routers that work together to transmit information to the correct user. An analog communications network consists of one or more switches that establish a connection between two or more users (Haring John, 2008). For both types of network, repeaters may be necessary to amplify or recreate the signal when it is being transmitted over long distances. This is to combat attenuation that can render the signal indistinguishable from the noise. Another advantage of digital systems over analog is that their output is easier to store in 
memory, i.e. two voltage states (high and low) are easier to store than a continuous range of states.

\section{Communication Channels}

The term "channel" has two different meanings. In one meaning, a channel is the physical medium that carries a signal between the transmitter and the receiver. Examples of this include the atmosphere for sound communications, glass optical fibers for some kinds of optical communications, coaxial cables for communications by way of the voltages and electric currents in them, and free space for communications using visible light, infrared waves, ultraviolet light, and radio waves (OECD, 1991). This last channel is called the "free space channel". The sending of radio waves from one place to another has nothing to do with the presence or absence of an atmosphere between the two. Radio waves travel through a perfect vacuum just as easily as they travel through air, fog, clouds, or any other kind of gas besides air.

The other meaning of the term "channel" in telecommunications is seen in the phrase communications channel, which is a subdivision of a transmission medium so that it can be used to send multiple streams of information simultaneously. For example, one radio station can broadcast radio waves into free space at frequencies in the neighborhood of $94.5 \mathrm{MHz}$ (megahertz) while another radio station can simultaneously broadcast radio waves at frequencies in the neighborhood of 96.1 MHz. Each radio station would transmit radio waves over a frequency bandwidth of about $180 \mathrm{kHz}$ (kilohertz), centered at frequencies such as the above, which are called the "carrier frequencies". Each station in this example is separated from its adjacent stations by $200 \mathrm{kHz}$, and the difference between $200 \mathrm{kHz}$ and $180 \mathrm{kHz}$ (20 $\mathrm{kHz}$ ) is an engineering allowance for the imperfections in the communication system.

In the example above, the "free space channel" has been divided into communications channels according to frequencies, and each channel is assigned a separate frequency bandwidth in which to broadcast radio waves. This system of dividing the medium into channels according to frequency is called "frequency-division multiplexing". Another term for the same concept is "wavelength-division multiplexing", which is more commonly used in optical communications when multiple transmitters share the same physical medium.

\section{Modulation}

The shaping of a signal to convey information is known as modulation. Modulation can be used to represent a digital message as an analog waveform. This is commonly called "keying" -a term derived from the older use of Morse Code in telecommunications- and several keying techniques exist (these include phase-shift keying, frequency-shift keying, and amplitude-shift keying). The "Bluetooth" system, for example, uses phase-shift keying to exchange information between various devices. In addition, there are combinations of phaseshift keying and amplitude-shift keying which is called (in the jargon of the field) "quadrature amplitude modulation" (QAM) that are used in high-capacity digital radio communication systems (Wheen, 2011). 
Modulation can also be used to transmit the information of low-frequency analog signals at higher frequencies. This is helpful because low-frequency analog signals cannot be effectively transmitted over free space. Hence the information from a low-frequency analog signal must be impressed into a higher-frequency signal (known as the "carrier wave") before transmission. There are several different modulation schemes available to achieve this [two of the most basic being amplitude modulation (AM) and frequency modulation (FM)].

\section{Factsheet of Telecom Companies in Saudi Arabia}

\section{STC}

STC is the largest telecommunication services provider in the Middle East and North Africa. It is the leading operator within the Kingdom of Saudi Arabia, and its international presence extends to 9 countries. Company is well-positioned to deliver growth to shareholders: Consistent history of success and delivering increases in key metrics, Strong market position in KSA and an expanding presence in key regional growth markets in which STC can leverage its expertise in the sector, Operating in growth markets - domestic and regional trends driving adoption of mobile and broadband services, Innovative solution delivery for customers across fixed, mobile and data products, Strategic approach to costs - STC is leveraging its investment in NGN (Next Generation Network) networks and international markets to create synergies that will reduce future OPEX, Strong balance sheet and healthy cash flow - well placed to gain access to substantial levels of debt to fund future investments if needed (STC Investor Factsheet).

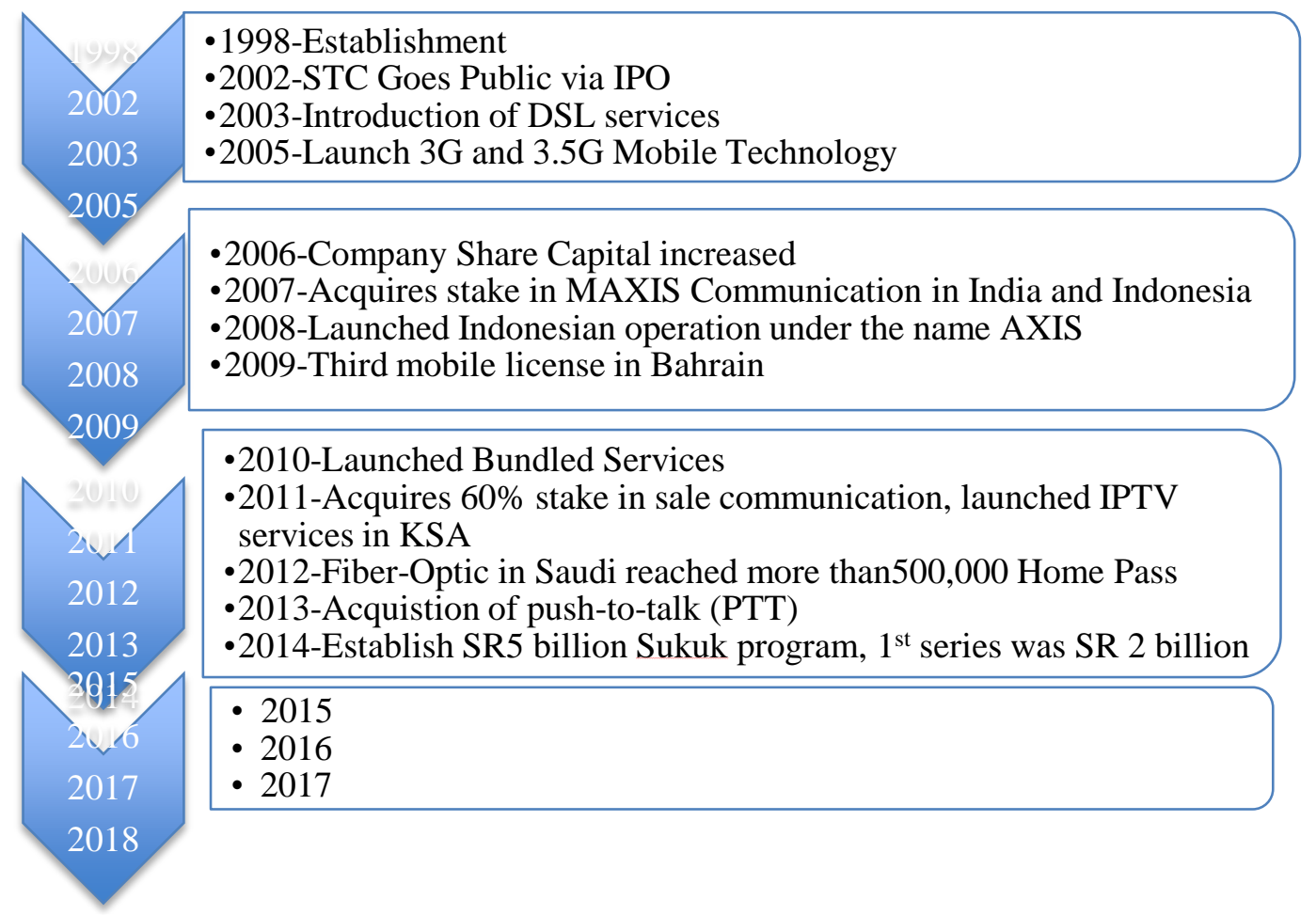

Figure 1. STC continuous growth year wise 


\section{Shareholder's structure 2018}

- 70\% Public Investment Fund

- $16.23 \%$ Public Float

- 7\% General Organization for Social Insurance

- $6.77 \%$ Public Pension

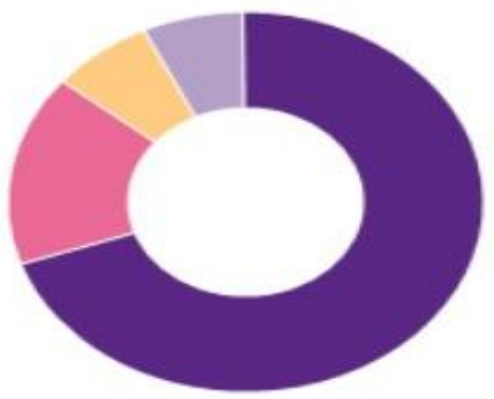

Figure 2. STC Shareholders Growth (As of 31st December 2018)

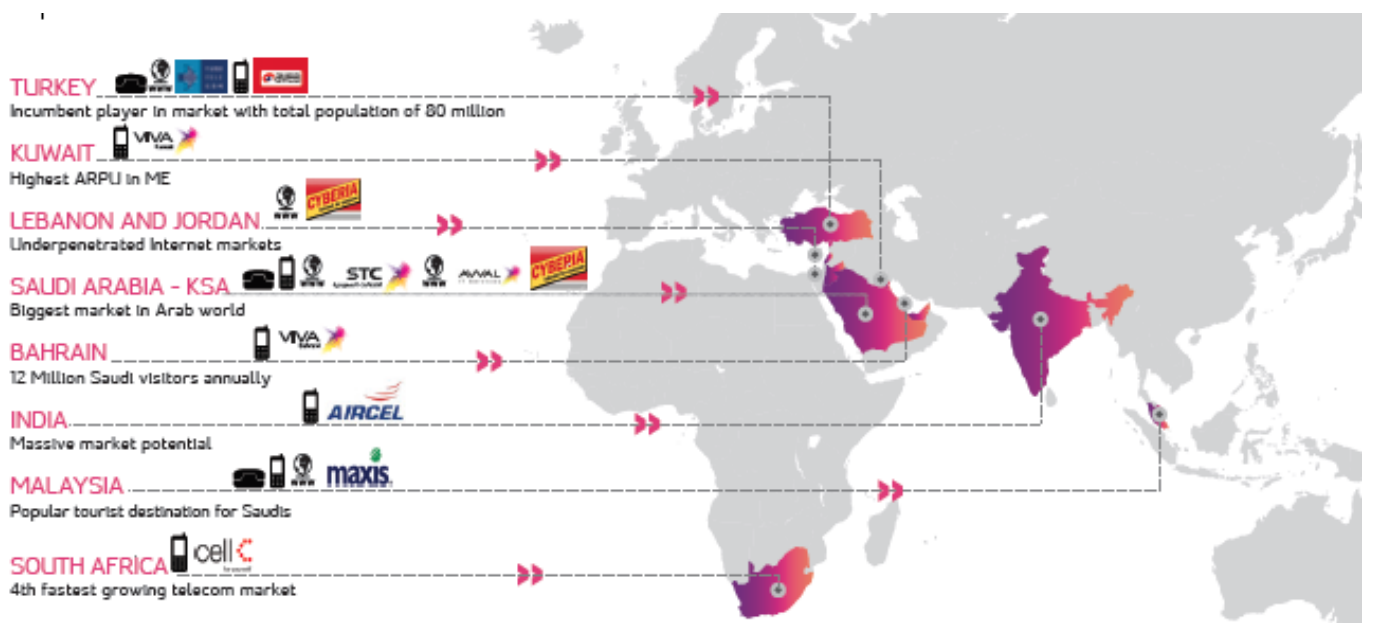

Figure 3. STC International Footprint (Data as of December 2019)

\section{STOCK INFORMATION \& SHARE PRICE}

$17 / 12 / 2019$

The site of the Saudi market (Tadawul) is the official source of stock information and the information contained on this page is only for illustration, Saudi Telecom Company does not assume any liability for investment decisions taken based on the information published on the site

SHARE PRICE

99.10 SAR

\begin{tabular}{lc} 
Previous Close Price & 99.00 \\
\hline Open Price & 99.00 \\
\hline High Price & 102.20 \\
\hline Low Price & 98.60
\end{tabular}

CHANGE \%

0.1

$\begin{array}{lr}\text { Volume Traded } & 1281130.0\end{array}$

$\begin{array}{ll}\text { Turnover } & 128780554.60\end{array}$

Number Of Trades

2556

Average Trade Size

501

Figure 4. STC Stock Information 
Revenues

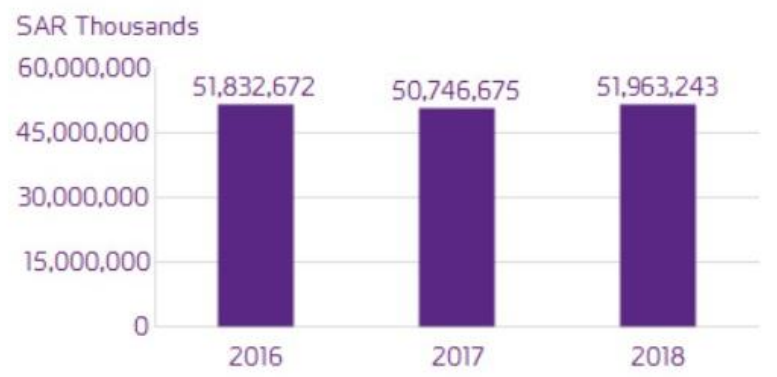

Net Profit

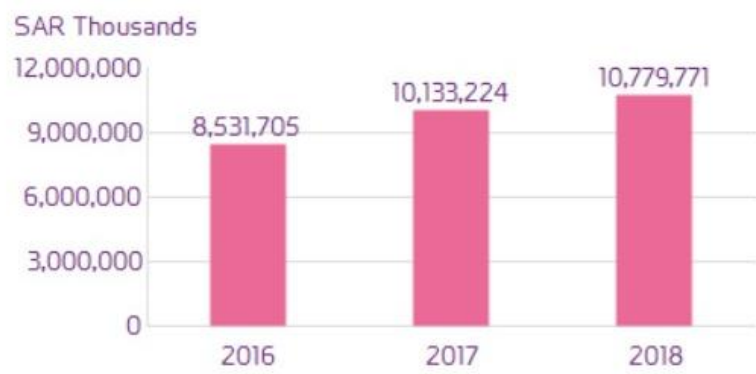

EBITDA

SAR Thousands

$25,000,000$

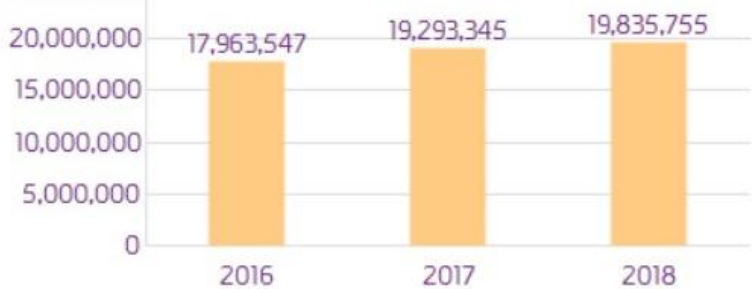

Shareholder's structure 2018

- 70\% Public Investment Fund

- $16.23 \%$ Public Float

- 7\% General Organization for

Social Insurance

- $6.77 \%$ Public Pension

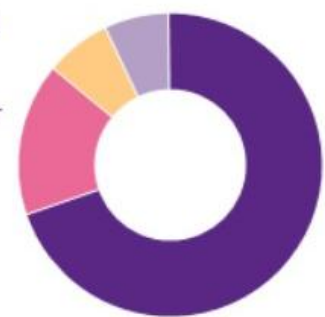

Figure 5. STC Financial Highlights

\section{ZAIN Telecom Company}

Zain Group (http://english.alarabiya.net/en/business/2014/01/27/Scott-Gegenheimer-scalling-to-steer-zain-through-better-times.html) is a mobile telecommunications company founded in 1983 in Kuwait as MTC or Mobile Telecommunications Company and was later rebranded to Zain in 2007. Zain has commercial presence in 8 countries across the Middle East and North Africa with 49.5 million active customers as of 31 December 2019.

Zain launched its commercial operations in the Kingdom of Saudi Arabia on 26 August 2008, a year after it was awarded its mobile license. The Group holds management control of the operation through its 37 percent ownership stake. Zain Saudi Arabia also offers 4G LTE services. Zain is listed on the Kuwait Stock Exchange. There are no restrictions on Zain shares as the company's capital is 100 percent free float and publicly traded. The largest shareholder is the Kuwait Investment Authority (24.24\%) (Smith, 2013).

For the first six months of 2014, Zain Group generated consolidated revenues of USD 2.23 billion (KD 627 million), up three percent year-on-year. The company's consolidated EBITDA for the period reached USD 943 million (KD 265 million), reflecting an increase of one percent Y-o-Y. Earnings per share for the period stood at USD 0.10 (KD 0.029) (www.commsmea.com/14400-zain-group-first-half-revenues-hit-223-billion.). 

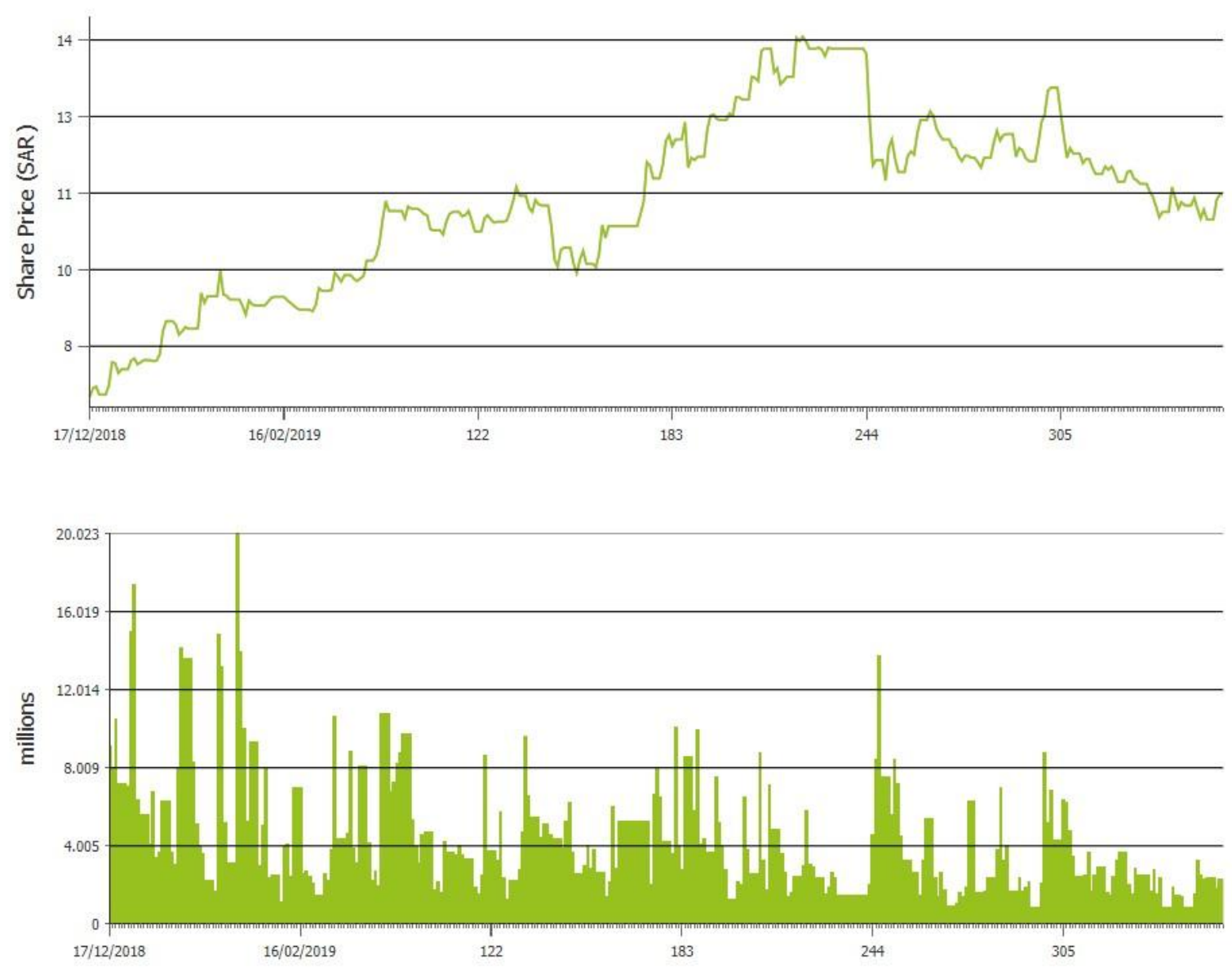

Figure 6. Zain Financial Chart

\section{The World of Zain}

\section{ZAIN'S WORLD CATERS TO 49 MILLION CUSTOMERS IN 8 COUNTRIES ${ }^{\star}$}

- exclusive of Morocco, in which Zain has a $15.5 \%$ ownership in the mobile | LEBANON Management Contract Customers: 2.4
Prepaid: $86 \%$

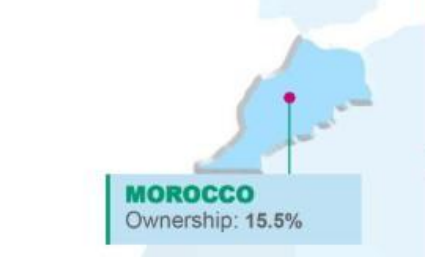

\section{JORDAN}

Ownership: $96.52 \%$

Revenues: $\$ 494 \mathrm{~m}$

Customers: $3.7 \mathrm{~m}$

Market Share: $36 \%$

Market Share: $36 \%$

SUDAN

Ownership: $100 \%$

Revenues: $\$ 316 \mathrm{~m}$

Customers: $14.6 \mathrm{~m}$

Market Share: $48 \%$

\section{SOUTH SUDAN}

Ownership: $100 \%$

Customers: $873 \mathrm{~K}$

Prepaid: $99 \%$

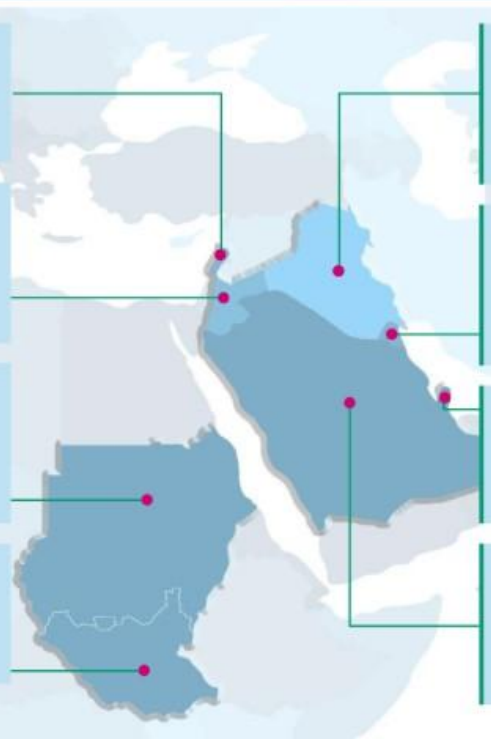

IRAQ

Ownership: $76 \%$

Revenues: $\$ 1.1 \mathrm{~b}$

Prepaid: $98 \%$

Market Share: $\mathbf{4 4 \%}$

operator "INWI"

KUWAIT

Ownership: $100 \%$

Revenues: $\$ 1.1 \mathrm{~b}$

Customers: $2.6 \mathrm{~m}$

Prepaid: $64 \%$

Market Share: $37 \%$

BAHRAIN

Ownership: $\mathbf{5 5 . 4 \%}$
Revenues: $\$ 176 \mathrm{~m}$

SAUDI ARABIA

Ownership: $37.05 \%$

Revenues: $\$ 2.0 \mathrm{~b}$

Customers: $8.1 \mathrm{~m}$

repaid: $52 \%$ 


\section{Shareholders}

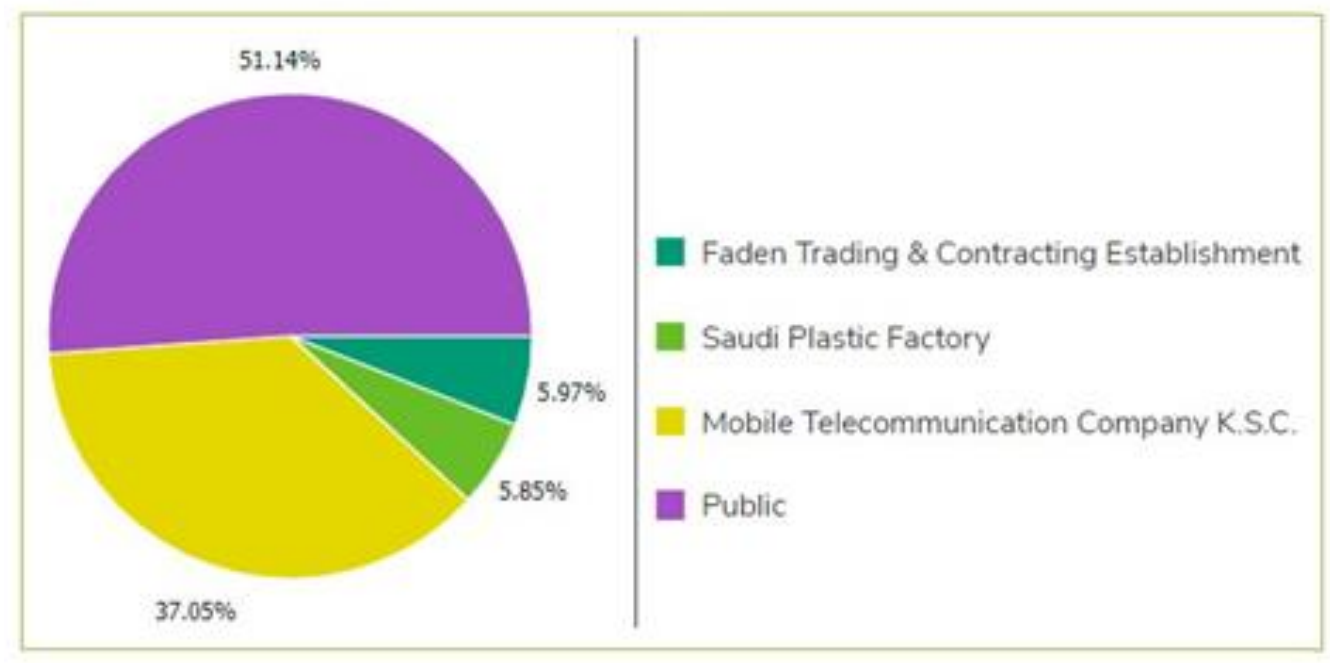

Figure 7. Zain Network Coverage and Shareholders

\section{Mobily Telecom Company}

Mobily is the trade name launched in May 2005 by Saudi Arabia's second telecommunications company, Etihad-Etisalat consortium. The company, as the winning bidder for Saudi Arabia's second GSM license in 2004, provides mobile telecom services nationwide, breaking Saudi Telecom's monopoly in the wireless business. The company launched 3.5G services on 27 June 2006 and 4G services on 13 September 2011 (Mobily Q4 profit rises 16 percent to SR1.7bn Arab News, 2012).

The consortium is led by United Arab Emirates firm Etisalat who owns 27 percent, with 45 percent held by 6 strategic local partners. The remaining 20 percent was put up in 2004 in an Initial public offering that was massively oversubscribed.

The GSM Associations "GSM Association Newsletter" Dec. 2004 edition described Mobily as the fastest growing mobile operator in the Middle East \& North Africa. In 2006, Mobily reached more than 4,800,000 subscribers. As of 20 January 2007, Mobily had 6 million subscribers and 0.5 million 3G users. Mobily introduced in 2004 the first telecommunication franchise business model in the Gulf Region, the Fully Branded outlet-(FBO), assuring rapid and cost-effective expansion of its network of outlets.

Since entering the Saudi market in 2004 Mobily adopted a solid expansion strategy, based on a direct and indirect sales channels. This strategy allowed Mobily to quickly expand and establish the Mobily Brand throughout Saudi Arabia, and as a result achieve its set target for 2006, both in terms of sales and revenue targets, unfortunately this has been achieved with other services and coverages being compromised as a result (Mobily hits one million user mark: announces expansion plan and new offers telegeography.com, 2005; Mobily Annual Report 07). 


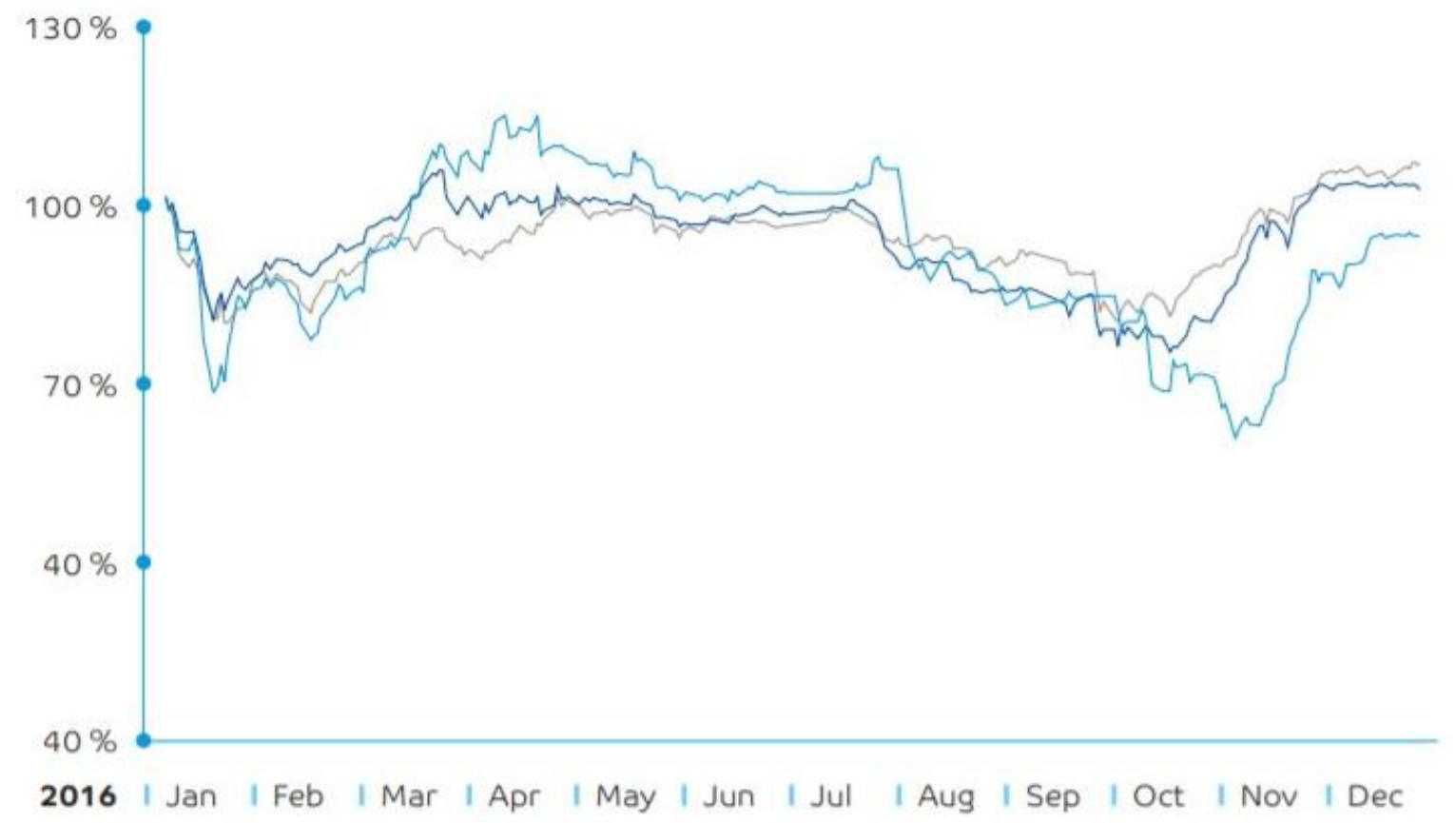

Information \& Technology Index

TASI

Mobily

Figure 8. Technical Analysis of Mobily

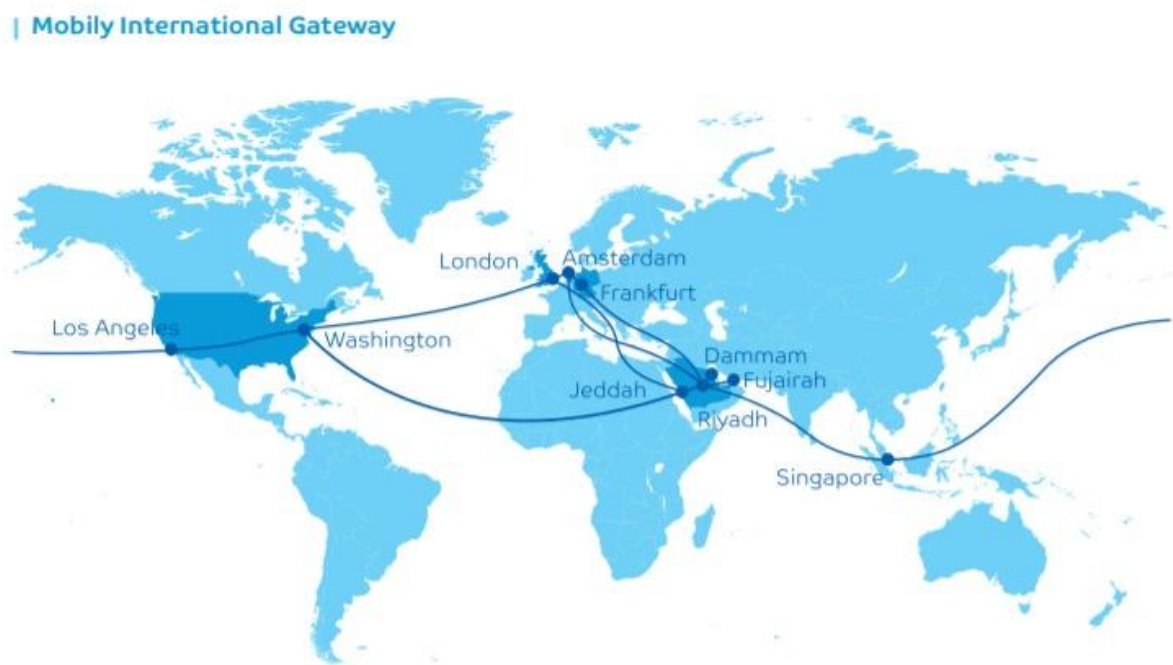

Figure 9. Mobily Coverage Area

In October 27, 2014 Mobily (Ettihad Etisalat IPO descends into chaos telegeography.com, 2004) was suspended from the Saudi Stock Exchange for failing to produce quarterly financial statements. Once they did, the delay was attributed to an accounting cover-up of earnings which were false over the course of 18 months, resulting in the company removing over 2 billion from its books. This resulted in its stock to fall 40 percent over the following week. As of November 18, 2014, no new statement has been submitted to quell allegations of 
embezzlement and fraud from upper management (Mobily launches 4G services Arab News, 2011).

\section{Technological Services}

\section{STC Services}

STC Group headquartered in Riyadh, Saudi Arabia, is the largest telecommunications company in the Middle East and Africa (MEA) based on market capitalization, generating over SAR 45.83 billion (USD 12.22 billion) in revenues in 2014 and SAR 10,96 billion (USD 2.92 billion) net income.

Launched in 1998, STC has a fiber-optic cable network spanning 137,000 kilometers across Asia, the Middle East, and Europe. STC in Saudi Arabia, the group's core business, runs a mobile network, covering more than 99 percent of the country's populated areas and enables 4th generation $(4 \mathrm{G})$ mobile broadband services to more than 85 percent of the population across Saudi Arabia.

Besides STC's main operation in Saudi Arabia with a 100 percent ownership, STC's footprint as a telecom operator covers Viva Bahrain with a 100 percent ownership, Viva Kuwait with a 51.8 percent ownership alongside a management contract, a 35 percent stake in Oger Telecom Ltd. UAE which controls all of Turk Telecom, Avea in Turkey and Cell-C in South Africa, a 25 percent ownership in Binariang GSM Holding Malaysia which controls both Maxis in Malaysia and Aircel in India. Additionally, STC has investments in IT, Content, Distribution, Contact Center, and Real Estate, all of which support its telecom operations across the Middle East.

STC services are divided into three broad categories: Jawal Al Amani Al Aaliyah (mobile network), Home (landline network), and Enterprise services.

Through a partnership with Saudi Telecom Company (STC), BT(Breakfast Television) announced today it has made it easier and more cost effective for multinational companies in Saudi Arabia to connect to their international operations by launching a local Point of Presence (PoP) of its global Multi-Protocol Label Switching (MPLS) network. The new PoP will be operated by STC in conjunction with its national and regional MPLS network. BT's MPLS platform is available in more than 170 countries around the world through BT and local licensed partners such as STC. As one of the largest global Internet Protocol (IP-based) networks, it underpins mission critical applications for leading global enterprises from a variety of industry sectors, including financial services, manufacturing, logistics, as well as oil \& gas and pharmaceutical industry. STC's MPLS network is based on the latest state-ofart technology and is extremely reliable and diverse. It is available to enterprises throughout the Kingdom as well as outside via its numerous PoPs in the Middle East region. Engineer Saad Demyati, vice president of STC's Wholesale business unit, stated: "STC has a solid track record of successful cooperation with BT both in the Kingdom as well as across the 
region. We believe that STC's strengths within the Kingdom and the region and BT's premier global presence will make this a very exciting and complementary partnership for the overall benefit of our domestic and international customers." Engineer Sameer Matbouly, Vice President of STC's Enterprise Business Unit added "This distinctive partnership between two of the leading companies in their fields will enable various enterprise customers to receive high quality and very efficient services at competitive prices that suit their needs and requirements. These customers are the cornerstone of the service industry that drives the economic cycle and national development to the forefront. This partnership also comes in line with STC's strategy which addresses its customer-centric approach and stays in tune and in touch with their needs while at the same time provides them with highly advanced and high quality services and solutions to ensure both the continuity and prosperity of their businesses within and outside the Middle East region. Our customers can now rest assured of high-quality managed services to all corners of the world on a very attractive cost-effective basis that is second to none in the region." Wael El Kabbany, managing director, BT Middle East and North Africa, says: "Kingdom of Saudi Arabia is the largest and one of the most vibrant ICT markets in the Middle East region and we are very excited of the business opportunities it offers. We believe this latest partnership will benefit not only companies in the Kingdom, but enterprises and operators across the whole region. We are proud of this cooperation with STC, a clear telecommunications leader within the region, and look forward to continue our fruitful collaboration." Peter Ashton, general manager BT Al Saudia, said: "We are proud to be participating with both BT and STC in providing world-leading global services to customers in Saudi Arabia. The new partnership will provide customers with extended high-capacity, high quality connectivity to sites worldwide."

\section{ZAIN Services}

Zain Group is a mobile telecommunications company founded in 1983 in Kuwait as MTC or Mobile Telecommunications Company and was later rebranded to Zain in 2007. Zain has commercial presence in 8 countries across the Middle East and North Africa with 44.3 million active customers as of 31 December 2014. It employs over 7000 people. The group CEO is Scott Gegenheimer, who was appointed in December 2012. Zain launched its commercial operations in the Kingdom of Saudi Arabia on 26 August 2008, a year after it was awarded its mobile license. The Group holds management control of the operation through its 37 percent ownership stake. Zain Saudi Arabia also offers 4G LTE services.

(Riyadh, Saudi Arabia, June 24, 2015) Zain KSA, a leading telecommunications provider in Saudi Arabia, and Huawei, have announced the launch of the first commercial LTEAdvanced Carrier Aggregation in two frequency bands (Band 1 and Band 3) network in the world. Following the launch of its popular LTE network in 2011, Zain has been focused on developing a more advanced mobile broadband experience to better serve its customers in Saudi Arabia. By launching an LTE-Advanced network in partnership with Huawei, Zain can offer superfast mobile speeds of up to $150 \mathrm{Mb} / \mathrm{s}$ with high bandwidth and compatibility with its existing nationwide LTE network. 
Heralded as the first of its kind in the world, the LTE-A network was developed by implementing Carrier Aggregation in two frequency bands (Band 1 and Band 3). The new network not only doubles its capacity but enhances the user speed upper limit from $75 \mathrm{Mbps}$ to $150 \mathrm{Mbps}$ in order to meet the growing levels of data usage from mobile subscribers in KSA. This commercial launch of Zain's new LTE-A network is an important part of its 'Winning through Caring' market strategy. In collaboration with its strategic partner Huawei, Zain also set up the 'Tech City' project in Saudi Arabia to establish protocols to understand the best user experience, aiming to achieve the best voice quality, web and video experience in the Saudi market. The LTE-A CA solution is one of many technologies intending to significantly enhance the network efficiency and improve the user experience speed.

"The launch of our new LTE-A network in Saudi Arabia is another step of our commitment to offer the best and most innovative solutions to our customers. As market trends continue to move toward high speed mobile data $\&$ video communication along with the proliferation of social applications, bringing unprecedented challenges to mobile broadband networks. We recognize LTE-A technology as the way of future connectivity," said Hassan Kabbani, CEO of Zain KSA.

Ramadan Ding, CEO Huawei Saudi Arabia, said: "The latest innovative solutions in mobile broadband connectivity are shaping the future of Saudi Arabia's telecom market. These technologies are increasingly viewed as enablers of continued economic and social development that support the government's vision of a knowledge-based digital economy. Huawei will continue to offer our partnership providing the latest mobile broadband innovations to help improve Zain's customer services." Through its partnership with Huawei, Zain has developed a series of solutions aimed at improving user experience, with the LTE-A CA solution one of these ground-breaking technologies. In line with its strategy, Zain will continuously strive for technological excellence in order to meet the increasing mobile internet demand in KSA.

\section{Mobily Services}

Mobily is the trade name launched in May 2005 by Saudi Arabia's second Telecommunications company, Etihad-Etisalat consortium. The company, as the winning bidder for Saudi Arabia's second GSM license in 2004, provides mobile telecom services nationwide, breaking Saudi Telecom's monopoly in the wireless business. The company launched 3.5G services on 27 June 2006 and 4G services on 13 September 2011. Mobily's employees include a sales team via its own flagship branches, Fully Branded Outlets, CoBranded outlets, Kiosks and thousands of dealers scattered throughout the country, covering the majority of the population.

This network of outlets and dealers was a major factor in Mobily rapid growth and customer acquisition. As a result, Mobily has earned a significant market share since launching operations on May 25, 2005. Mobily has launched a mobile push-to-talk service (PTT) under 
the brand name 'Mobily Hawwel' in Saudi Arabia. The PTT service provides users with a different user experience to the traditional voice service, delivering a 'walkie-talkie' like experience - only one person can talk at a time. However, it is not limited in distance as with normal walkie-talkies, as the conversation is carried across the mobile GSM network. This service is being offered for the first time in the country.

The service can provide a one to one voice service or up to 10 people at the same time as group calling, allowing a user to know who is online through small icons appearing with certain colors. Mobily said that the service will be available for post-paid and pre-paid subscribers at monthly fees. Mobily Hawwel conversations are encrypted over GPRS data or $3 \mathrm{G}$ network to avoid crosstalk or listening-in. This will be accomplished with the execution of an ambitious expansion plans for its own network of flagships, as well as introducing a new franchise retail concept (Mini-FBO). The new concept (Mini-FBO) will complement the existing Mobily retail and channel partner outlets, and will cover more than 60 cities and towns, which will help achieve its targets, both in terms of sales and customer experience. Those outlets, as is the case with the Mobily flagships, will provide the full range of products and services to the current and future customers of Mobily. On September 13, 2011 Mobily launched TD-LTE (4G) services, becoming the first operator in the Middle East and North Africa to do so.

In May 2013, it was reported that Mobily is working on a way to intercept encrypted data sent over the Internet by Twitter, Viber, WhatsApp, and other mobile apps, and to bypass the protections built into the SSL and Transport Layer Security protocols.

\section{Telecom Market Sharing of STC, Zain And Mobily}

Saudi Arabia is impressive at almost 200 percent mobile penetration, and even more interesting due to the low penetration of fixed broadband (5.5\%). The mobile market in KSA was originally dominated by a government-owned company called STC. The market has been liberated over the years as additional licenses were given to two additional operators, called Mobily and Zain. The sector has a total of $42 \mathrm{mn}$ subscribers, out of which the market share for the 3 players (STC, Mobily and Zain) is a bit difficult to decipher. What is quite evident is that STC is the largest player in the market and in our view holds somewhere between 52-54 percent of the market, the rest is being shared between Zain and Mobily. Zain in its recent announcement highlighted that its subscribers base at the end of Q1-2018 stood at 8.4mn, depicting a market share of 18 percent. Leaving Mobily with a market share in the range of 28 to 30 percent. On the revenue front similar to the subscriber base, in 2017, STC accounts for roughly 60 percent of the total mobile subscribers' revenue, Mobily accounted for 25 percent of the Mobile subscriber's revenue, while Zain's market share in mobile revenues stood at 16 percent (Dan Goodin, 2013). 


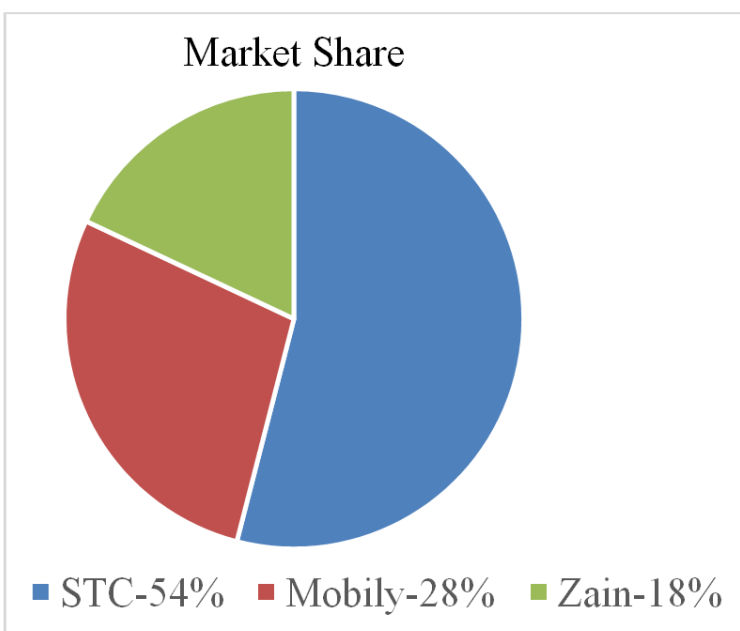

Figure 10. Subscriber Market Share of Operator

Table 1. Quick Facts Saudi Arabia

\begin{tabular}{|l|l|}
\hline \multicolumn{1}{|c|}{ Quick Facts } & \multicolumn{1}{c|}{ Saudi Arabia } \\
\hline Land Area & 2.15 million $\mathrm{km}^{2}$ \\
\hline Population & 33.85 million (2019) \\
\hline GDP per capita & 23,338.96 USD (2019) \\
\hline TLD & .sa \\
\hline Fixed Telephone & 3.6 million (2019) \\
\hline GSM Telephone & 51 million (2019) \\
\hline Fixed Broadband & 3.88 million (2019) \\
\hline Internet Users & 22.3 million (2019) \\
\hline
\end{tabular}

After going through a rough patch in 2016 and 2017 due to the fingerprint registration, decline in expat population and the general slowdown in economy, the telecom sector is expected to show some improvement. Limited growth opportunities due to high saturation levels in voice and data will keep growth muted. However, a reversal in trend was seen in the last CITC report for Q1-2018. According to data released by CITC, mobile subscribers at the end of Q1-2018 stood at 42mn subscribers, a significant improvement over 40.2mn subscriber base towards the end of 2017, depicting a jump of 4.5 percent QoQ. Since the start of 2015, mobile subscribers have seen a significant drop from a high of $53 \mathrm{mn}$.

The current increase can be indicative of the reversal in trend. What is more significant is the mix of customer base. Although Prepaid customers still form the large chunk of total subscribers, postpaid subscribers have started to show an increase. In Q1-2018 postpaid customers stood at $11.2 \mathrm{mn}$, accounting for 27 percent of the total mobile subscriber base, mounting a jump of 10.9 percent YoY, whereas in 2017 postpaid customers showed a jump of 27.9 percent YoY, depicting a relatively resilient customer mix. A higher number of postpaid customers will also mean that market share of the three operators will remain fairly constant, as is our belief that postpaid customers are stickier as compared to prepaid. 


\section{Mobile Subscribers}

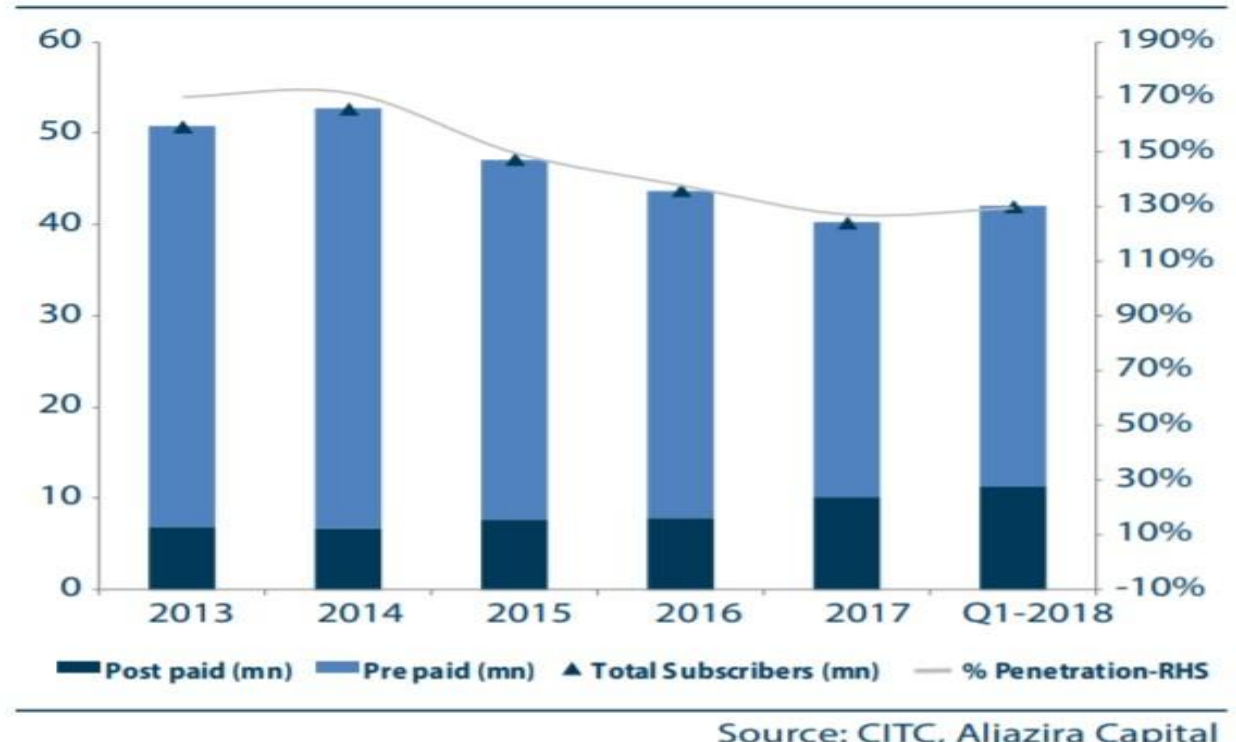

Figure 2. Mobile Service Market Growth

It has become easier to access the internet via mobile devices such as smart phones. The mobile networks are also improving, as the 3.5G (HSPA) continues to be deployed and as wireless broadband (technologies (4G emerge over the next few years. Fixed line in 1Q-2018 stood at $3.72 \mathrm{mn}$ household subscribers, reaching a household penetration level of 35.4 percent, depicting a QoQ jump of 2.2 percent. Residential lines growth fared slightly better than business lines with 2.9 percent QoQ growth. STC is the prime player in the fixed line market, which in our view bodes well for the company.

\section{Fixed Broadband Subscribers}

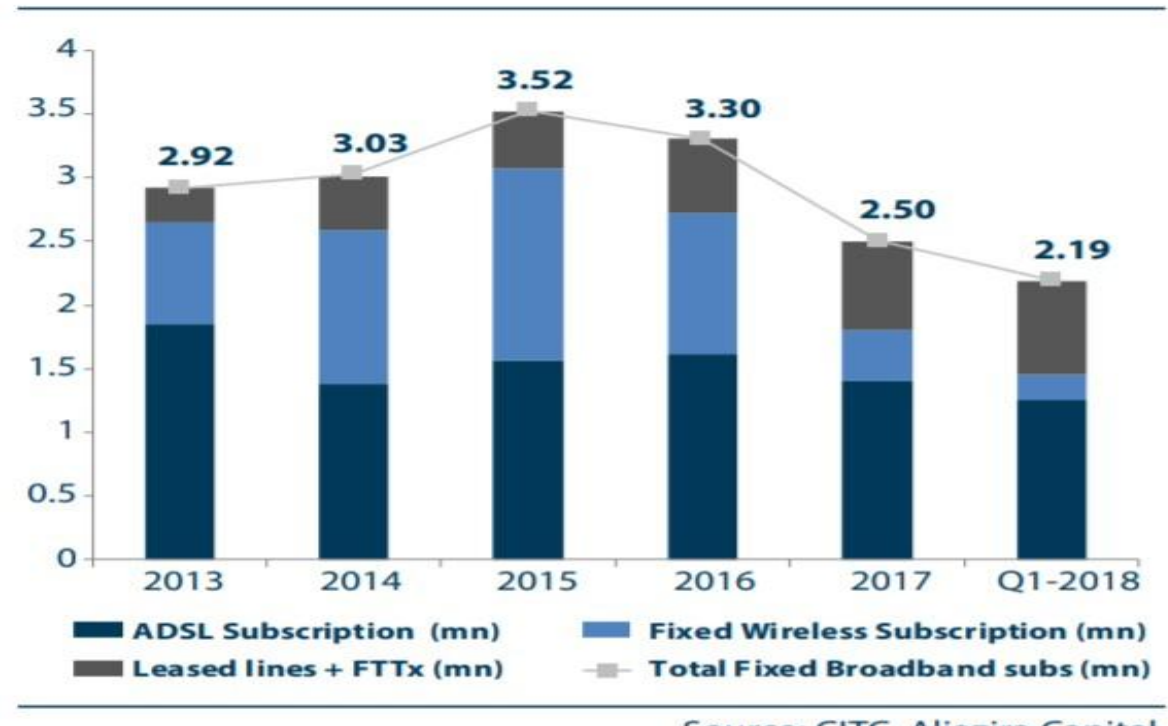

Figure 13. Fixed Broadband Subscriptions 
The total number of mobile broadband subscriptions decreased to reach around 25.25 million by the end Q3 2016, for all subscriptions representing a population penetration rate of 78.8 percent. The decreasing is due to the new fingerprint requirement for all subscriptions, and it is expected to continue decreasing in the upcoming period.

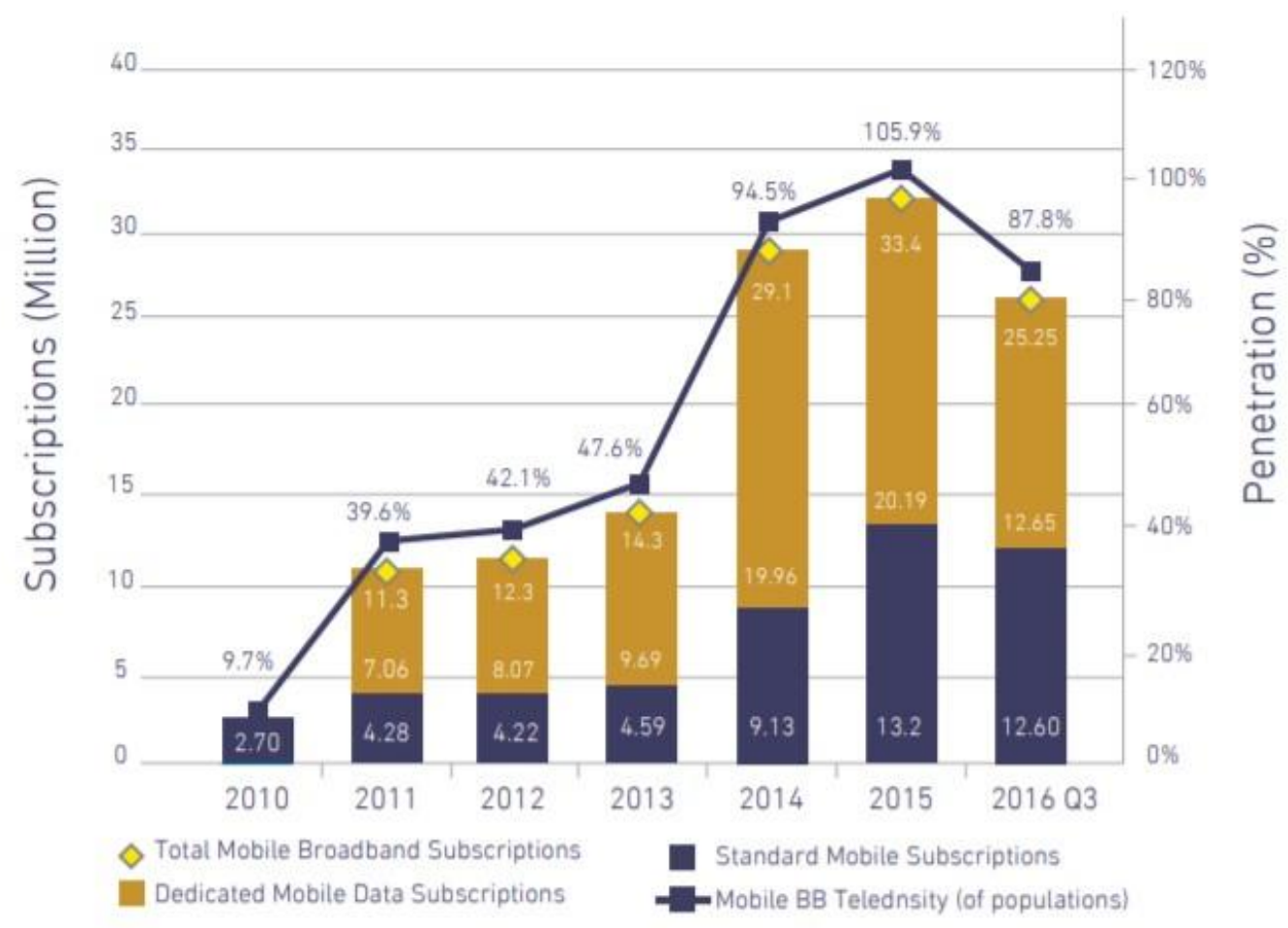

Figure 14. Mobile Broadband Subscriptions

\section{Mobile Internet Subscribers}

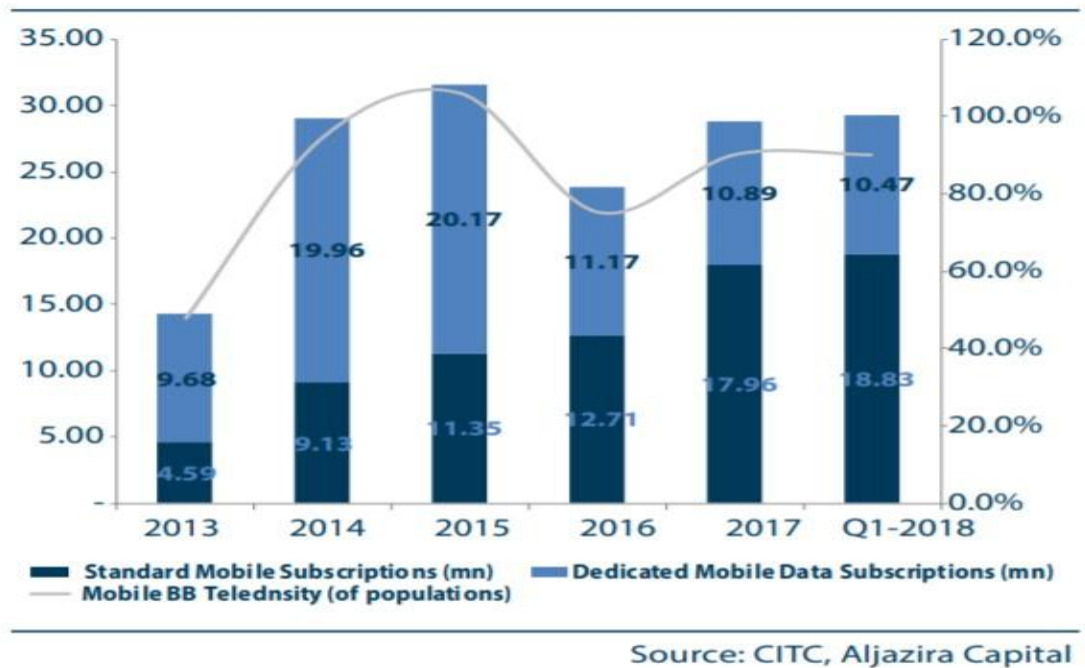

Figure 15. Internet Market Evaluation

Unlike the mobile subscriber base, internet subscribers have seen a significant drop, Fixed broadband has gone down to 2.2mn subscriber in 1Q-2018, from 2.5mn in 4Q-2017, a QoQ drop of 12.4 percent. ADSL and Fixed wireless subscribers both have shown a decline of 
10.7 percent QoQ and 50 percent QoQ respectively. However leased line and FTTX have shown a slight increase of 5.7 percent QoQ. It should be mentioned that STC is the prime player in the fixed broadband segment of ADSL and leased lines, any loss in subscriber base will have a direct impact on the company. Mobile broadband has shown an increase of 1.56 percent QoQ, driven by 4.8 percent QoQ increase in standard mobile subscriber (Voice+Data), whereas dedicated mobile data subscribers have seen a decline by 3.86 percent QoQ.

\section{Conclusion}

There was a time, when the only telephone service provider in Saudi Arabia was STC - Saudi Telecom Company. Those were days of costly local and international calls. The scenario suddenly changes with entry of UAE based Etisalat telecom operator through the name Mobily. International calls had become affordable and locals were also cheap. Having a mobile was easy for common man and gone were the long lines in Batha for sim card. The competition drove the call rates lower and lower and every few months there offer from one company and immediate counteroffer from the other telecom company. Those were days, when advertising boards only showed STC and Mobily. The entry of Zain was much advertised but it did not live up to its image. There was not much change in the market rates. Zain's connectivity and range still raises some questions. To know the best at any time, you can visit the website of companies and compare. We tried working on preparing a comparison for different service providers, but with everyday changing rates, it was hard to keep up to date.

\section{References}

Alarabiya. Retrieved December 15, 2019, from http://english.alarabiya.net/en/business/2014/ 01/27/Scott-Gegenheimer-s-calling-To-steer-Zain-through-better-times.html

Commsmea. Retrieved December 15, 2019, from http://www.commsmea.com/14400-zain-groupfirst-half-revenues-hit-223-billion.

Communication and Information Technology Commission, Saudi Arabia, Annual Report 2005. Communication and Information Technology Commission. Retrieved 2007-01-22.

Definition of telecommunication. 2019. Yahoo. Retrieved December 15, 2019, from

Electronic Newsletter (2016). June. H 1437 Ramadan: Issue / 25 Version. Retrieved December 15, 2019, from http://citc.gov.sa

Ettihad Etisalat IPO descends into chaos (2004). Telegeography.com, 25 Oct 2004. Retrieved December 15, 2019, from

Goggin, G. (2011). Global Mobile Media (New York: Routledge, 2011), p. 176. ISBN 9780415469180 .

Goodin, D. (2013). Dear hacker: Please help us eavesdrop on our customers, Arstechnica, May 13, 2013. 
Haring, J. (2008). Telecommunications. In David R. Henderson (ed.). Concise Encyclopedia of Economics (2nd ed.). Library of Economics and Liberty.

Mobily (2019). Q4 profit rises 16\% to SR1.7bn Arab News. Retrieved December 15, 2019, from https://www.arabnews.com/

Mobily annual report (2019). http://www.mobily.com.sa/

Mobily hits one million user mark (2005). Announces expansion plan and new offers. Retrieved December 15, 2019, from http://www.telegeography.com

Mobily launches 4G services (2011). Arab News, Sep 13, 2011.

Mobily.com.sa. Retrieved January 15, 2020, from http://www.mobily.com.sa

Moxie Marlinspike (2013), A Saudi Arabia Telecom's Surveillance Pitch, May 13, 2013.

OECD (1991), Universal Service and Rate Restructuring in Telecommunications, Organisation for Economic Co-operation and Development (OECD) Publishing, 1991. ISBN 92-64-13497-2.

Smith, M. (2013). Zain's Lebanon telecom contract to be rolled over again -CEO. Reuters, September 24, 2013.

STC Investor Factsheet. Riyadh-11652, Saudi Arabia. Retrieved December 15, 2019, from

STC.com.sa. Retrieved January 15, 2020, from https://www.stc.com.sa/

Telecommunication (2013). Oxford Dictionaries. Oxford University Press.

Telecommunication (2013). Retrieved December 15, 2019, from http://www.dictionary.com.

Telecommunication (2019). Collins English Dictionary. Retrieved December 15, 2019, from

Telecommunication (2019). Merriam-Webster Dictionary. Retrieved December 15, 2019, from

Telecommunication (2019). Retrieved December 15, 2019, from http://www.vocabulary.com.

Wheen, A. (2011). Dot-Dash to Dot.Com: How modern telecommunications evolved from the telegraph to the Internet. Springer. ISBN: 978-1-4419-6760-2.

Zain.com. Retrieved January 15, 2020, from https://www.zain.com/

\section{Bibliographic information of this paper for citing:}

Kumar Singh, A., \& Dwivedi Sharma, S. (2020). "Digital era in the Kingdom of Saudi Arabia: Novel strategies of the Telecom service providers companies." Webology, 17(1), Article 219. Available at: http://www.webology.org/2020/v17n1/a219.pdf

Copyright (C) 2020, Arun Kumar Singh and Samidha Dwivedi Sharma. 